\title{
Real-time video consultation during endoscopy: very welcome but plenty of questions!
}

\section{다 (i)}

\author{
Author \\ Roland Valori \\ Institution \\ Gloucestershire Hospitals, Gloucester, UK \\ Bibliography \\ Endosc Int Open 2021; 09: E1863-E1864 \\ DOI 10.1055/a-1613-5089 \\ ISSN 2364-3722 \\ (c) 2021. The Author(s). \\ This is an open access article published by Thieme under the terms of the Creative \\ Commons Attribution-NonDerivative-NonCommercial License, permitting copying \\ and reproduction so long as the original work is given appropriate credit. Contents
}

\author{
may not be used for commercial purposes, or adapted, remixed, transformed or \\ built upon. (https://creativecommons.org/licenses/by-nc-nd/4.0/) \\ Georg Thieme Verlag KG, Rüdigerstraße 14, \\ 70469 Stuttgart, Germany \\ Corresponding author \\ Roland Valori, MD FRCP, Gloucestershire Hospitals, \\ Great Western Road, Gloucester GL1 3NN, UK \\ Fax: +03004226892 \\ roland.valori@nhs.net
}

In an ideal world, a decision about what is in a patient's best interests should not be constrained by available expertise to manage the problem. This is particularly the case for removing polyps from the colon, when there is always time to assess lesions properly, consider the options and, if these are finally balanced, share the decision with the patient.

We are very far from this ideal. There is unacceptable variation in polypectomy outcomes [1] and rates of surgery for benign colorectal disease are increasing when they should be in decline [2]. There is plenty of evidence showing that endoscopic removal of larger polyps is effective, safer, and cheaper than surgery [3-5], so why is there so much variation in outcomes and why are so many patients having operations for benign disease?

At the heart of the problem is lack of knowledge about what is possible and inadequate expertise to remove large polyps, coupled with lack of clear pathways to access such expertise. If it is impossible, or just difficult, to refer a patient elsewhere, the easy option is to "give it a go," or ask a local surgeon. Surgical expertise to remove part of the colon is widespread. In contrast, the required endoscopic expertise often is not available locally, and in some instances, it may be many hours away. Even when it is not far away, there are no well-defined pathways making it at least as easy to refer to endoscopy as to surgery.

Of course, there are other issues, such as complex and varied scoring systems for polyps and differences of opinion about the optimal way to remove polyps. These factors are compounded by a general lack of awareness about what is possible and lack of appreciation of the impact on a patient when procedures are not done properly. There are cultural influences and, in some jurisdictions, perverse financial incentives affecting clinical decisions.

In some units it will be possible to ask a colleague to "pop in" to provide advice about a polyp: What type of polyp is it? What is the risk of malignancy? Should I leave it to someone else and if not, what technical approach should I take? If removing the lesion is beyond the expertise of the endoscopist, the expert colleague may be able deal with the lesion then, or at later date. Unfortunately, such expertise is usually not at hand.

The endoscopy team from Southern Denmark have a potential solution for providing immediate advice about polyp assessment and removal [6]. They report a feasibility study of realtime conference between an endoscopist who needs advice and an expert able to provide that advice, but working in a remote location. There remains a lot to do to get this right, but with rapidly improving conferencing capability, there is no reason why remote support for endoscopic procedures (the Zoom equivalent of a colleague "popping in") should not be commonplace.

We can assume that the technical challenges the Danes encountered will be overcome. This is an application of established, not new technology; it just needs tweaking. The main obstacles to widespread adoption are lack of perceived need, availability of expert advice, and robust funding mechanisms. There also will be medico-legal, political, and cultural barriers to overcome. But it is possible, it is likely to make a difference to decision-making, and it will have other beneficial effects, such as training those who seek advice and potentially creating a library of cases for more widespread learning. So how can endoscopy conferencing become mainstream? 
First, we need more examples of endoscopy conferencing to tease out the technical problems: to make the process so slick there is no technical barrier to seeking advice. These studies need to determine not just the feasibility, but also the practicalities of the service: who will be on call and for how long; how many endoscopy units it is possible to cover; whether it is better to have several experts available, in case one or more are busy; and whether there are clear pathways for patients who need to go elsewhere for their polypectomy. We need further evidence of impact: what proportion of calls were answered; what the outcome was of the advice; how many operations were saved; how many patients were referred on; whether the polyps were removed safely and completely. Critically, we need to know the costs, not just of providing the technology, but most importantly the absolute and opportunity cost of expert advice.

The expert needs to be able to stop doing whatever they were doing to provide immediate advice. This effectively precludes being "on call" during an endoscopy list, and possibly other activities such as clinics and ward rounds. But we all need periods "in the office" and these might be the best times to be available and, as such, they may not be that expensive.

Without cost-effectiveness analyses it will be difficult to attract the resources needed to develop endoscopy conferencing. Eventually, endoscopy units will have to pay for advice. Payments are probably best insurance-based (licensed), rather than payment per case, as the latter will be a barrier to seeking help. Use of the service could be incentivized, for example, with CPD points for each call. On the other hand, careful monitoring of polypectomy outcomes (particularly incomplete resection) and surgical referrals will enable services to challenge those who don't use the service.

The pandemic has accelerated the use of technology to improve communication. In health care, both health professionals and patients have accepted and become more familiar with remote interactions. There is an obvious role for it in supporting decision-making in endoscopy that could expand well beyond decisions about polypectomy. We now need cost-effectiveness studies to determine how to use it, and to justify implementing it.

\section{Competing interests}

The authors declare that they have no conflict of interest.

References

[1] Kaltenbach T, Anderson JC, Burke CA et al. Endoscopic removal of colorectal lesions-Recommendations by the US Multi-Society Task Force on Colorectal Cancer. Gastroenterology 2020; 158: 1095-1129

[2] Peery AF, Cools KS, Strassle PD et al. Increasing rates of surgery for patients with nonmalignant colorectal polyps in the United States. Gastroenterology 2018; 154: 1352-1360

[3] Ahlenstiel G, Hourigan LF, Brown G et al. Actual endoscopic versus predicted surgical mortality for treatment of advanced mucosal neoplasia of the colon. Gastrointest Endosc 2014; 80: 668-676

[4] Jayanna M, Burgess NG, Singh R et al. Cost analysis of endoscopic mucosal resection vs surgery for large laterally spreading colorectal lesions. Clin Gastroenterol Hepatol 2016; 14: 271-278

[5] Keswani RN, Law R, Ciolino JD et al. Adverse events after surgery for nonmalignant colon polyps are common and associated with increased length of stay and costs. Gastrointest Endosc 2016; 84: 296303

[6] Deding U, Hoegh A, Buch N et al. EndoConf: real-time video consultation during endoscopy; telemedicine in endoscopy at its best ETC. Endosc Int Open 2021; 09: E1847-E1851 